\title{
artigo
}

Ferraz, R.M.; Kron-Rodrigues, M.R.; Galvão, H.M.; Araújo, C.L.O.;

Metodologias ativas de ensino e aprendizagem: o ensino de hoje na saúde

\section{Metodologias ativas de ensino e aprendizagem: 0 ensino de hoje na saúde}

\author{
Active teaching and learning methodologies: today's in health education \\ Metodologías activas de enseñanza y aprendizaje: la educación actual en salud
}

\begin{abstract}
RESUMO
Objetivo: Identificar e descrever as metodologias ativas de ensino e aprendizagem e a modificação no movimento de ensino da saúde. Método: Trata-se de uma revisão bibliográfica, de caráter descritivo e abordagem qualitativa, realizada em bancos de dados Ciências da Saúde, incluindo a Scientific Electronic Library Online (SciELO), América Latina e Caribe em Ciências da Saúde Literatura (LILACS) e BDENF (Banco de Dados de Enfermagem) - por meio da Biblioteca Virtual em Saúde. A busca e coleta dos dados ocorreu no primeiro semestre de 2019. Resultados: Metodologias baseadas em problemas e projetos, Metodologia de Aprendizagem baseada em Projetos, Taxonomia de Bloom e Método de Delphi, Aplicativos Móveis podem ser considerados as metodologias ativas atuais no processo ensino-aprendizagem. Conclusão: 0 papel do professor, enquanto facilitador no processo de ensino-aprendizagem, é fundamental no sentido de adequar-se às novas demandas, abrir-se para as novas práticas pedagógicas, aceitar os desafios que a educação de hoje e do futuro imprimem.
\end{abstract}

DESCRITORES: Educação Profissionalizante; Educação em Saúde; Pessoal da Educação.

\section{ABSTRACT}

Objective: To identify and describe the active teaching and learning methodologies and the change in the health teaching movement. Method: This is a bibliographic review, of a descriptive character and qualitative approach, carried out in Health Sciences databases, including the Scientific Electronic Library Online (SciELO), Latin America and the Caribbean in Health Sciences Literature (LILACS) and BDENF (Nursing Database) - through the Virtual Health Library. The search and collection of data occurred in no first semester of 2019. Results: Methodologies based on problems and projects, Learning Methodology based on Projects, Bloom's Taxonomy and Delphi Method, Mobile Applications can be considered the current active methodologies in the teaching-learning process.. Conclusion: The role of the teacher, as a facilitator in the teaching-learning process, is fundamental to adapt to the new demands, to open up to the new pedagogical practices, to accept the challenges that the education of today and the future impose. DESCRIPTORS: Vocational Education; Health Education; Education Personnel.

\section{RESUMEN}

Objetivo: Identificar y describir las metodologías activas de enseñanza y aprendizaje y el cambio en el movimiento de enseñanza en salud. Método: Se trata de una revisión bibliográfica, de carácter descriptivo y enfoque cualitativo, realizada en bases de datos de Ciencias de la Salud, incluyendo la Biblioteca Científica Electrónica en Línea (SciELO), Latinoamérica y el Caribe en Literatura en Ciencias de la Salud (LILACS) y BDENF. (Base de datos de enfermería) - a través de la Biblioteca Virtual en Salud. La búsqueda y recolección de datos ocurrió en primer semestre de 2019. Resultados: Metodologías basadas en problemas y proyectos, Metodología de aprendizaje basada en proyectos, Taxonomía de Bloom y Método Delphi, Aplicaciones móviles pueden considerarse las metodologías activas actuales en el proceso de enseñanza-aprendizaje. Conclusión: El rol del docente, como facilitador en el proceso de enseñanza-aprendizaje, es fundamental para adaptarse a las nuevas demandas, abrirse a las nuevas prácticas pedagógicas, aceptar los desafíos que impone la educación de hoy y del futuro.

DESCRIPTORES: Educación Vocacional; Educación para la Salud; Personal de Educación.

RECEBIDO EM: 06/01/2021 APROVADO EM: 11/01/2021

\section{Raquel Martins Ferraz}

Discente do Programa de Pós-Graduação Stricto Sensu em Design, Tecnologia e Inovação - Mestrado Profissional do Centro Universitário Teresa D'Ávila - UNIFATEA.

ORCID: 0000-0003-2675-804X 


\section{Meline Rossetto Kron-Rodrigues}

Docente do Programa de Pós-Graduação em Enfermagem - Mestrado e Doutorado Universidade Univeritas (UNG) Guarulhos. ORCID: 0000-0003-2174-268X

\section{Henrique Martins Galvão}

Docente do Programa de Pós-Graduação Stricto Sensu em Design, Tecnologia e Inovação - Mestrado Profissional do Centro Universitário Teresa D'Ávila - UNIFATEA.

ORCID: 0000-0002-8017-6537

\section{Cláudia Lysia de Oliveira Araújo}

Docente do Programa de Pós-Graduação Stricto Sensu em Design, Tecnologia e Inovação - Mestrado Profissional do Centro Universitário Teresa D'Ávila - UNIFATEA.

ORCID: 0000-0002-0366-1475

\section{INTRODUÇÃO}

A educação é um processo sistemático e interativo de troca de informaçôes entre pessoas de uma dada comunidade, com o propósito específico de ajudá-las a elaborar conhecimentos e significados, incorporando-os a sua estrutura cognitiva e ao patrimônio cultural coletivo ${ }^{(1)}$. Trata-se de uma atividade individual e coletiva, mas que, por definição, diz respeito à construção e organização social.

A educação não é apenas um processo institucional e instrucional, mas também um instrumento formativo do humano, seja na particularidade da relação pedagógica pessoal, seja no âmbito da relação social coletiva, sem perder as referências éticas e políticas, tendo como premissa que o processo de formação de um sujeito ético, ou de um cidadão, vai depender da própria construção do sujeito humano ${ }^{(2)}$.

O grande desafio deste início de século é a crescente busca por metodologias inovadoras que possibilitem uma prática pedagógica capaz de ultrapassar os limites do treinamento puramente técnico e tradicional, para efetivamente alcançar a formação do sujeito como um ser ético, crítico, reflexivo, transformador e humanizado ${ }^{(3)}$.

Seguindo esse mesmo entendimento, a literatura afirma ${ }^{(4)}$ que na ABP (Aprendizagem Baseada em Problemas), o aluno parte de problemas ou situações que objetivam gerar dúvidas, desequilíbrios ou perturbações intelectuais, com forte motivação prática e estímulo cognitivo para evocar as reflexões necessárias à busca de adequadas escolhas e soluções criativas.

Com base nessa assimilação, observa-se que os conceitos de conscientização, emancipação, transformação social, somados aos de autoconhecimento e autorreflexão são tidos como essenciais na definição de objetivos educacionais para dirigir o processo de ensino-aprendizagem na metodologia da problematização ${ }^{(5)}$.

Pesquisadores ${ }^{(6,7)}$ entrevistaram discentes sobre as fortalezas e fragilidades dos métodos ativos de aprendizagem. A análise desse material foi guiada pela 'hermenêutica dialética', tendo como referência os princípios do 'método de interpretação de sentidos'. Seus resultados apontaram para o fato de que as Metodologias Ativas de Ensino e Aprendizagem (MAEAs) estimulam o estudo constante, a independência e a responsabilidade, possibilitam a integração das dimensões biopsicossociais, preparam para o trabalho em equipe e aproximam os alunos dos usuários e da equipe. No entanto, esses autores afirmam que os sentidos extraídos das falas dos estudantes indicam que nem todos estão preparados para isso; algumas vezes, sentem-se perdidos em busca de conhecimentos, além de apresentarem dificuldades quanto a sua inserção na equipe de saúde.

Ganha destaque nesse cenário o emprego das metodologias ativas de ensino, onde o sujeito é estimulado a processos construtivos de ação-reflexão-ação, em que o estudante tem uma postura ativa em relação ao seu aprendizado, que se dá numa situação prática de experiências, por meio de problemas que lhe sejam desafiantes e permitam pesquisar e descobrir soluções aplicáveis à realidade ${ }^{(7)}$.

As MAEAs estão fundamentadas na ideia do estudante como responsável pela própria busca do conhecimento, cabendo ao professor o papel de facilitador e estimulador desta busca ${ }^{(8)}$.

Dado o exposto, objetivou-se identificar e descrever as metodologias ativas de ensino e aprendizagem e a modificação no movimento de ensino da saúde.

\section{MÉTODO}

Trata-se de uma revisão bibliográfica, de caráter descritivo e abordagem qualitativa ${ }^{(9)}$.Foram utilizadas as palavras-chaves: "educação profissionalizante", "educação em saúde" e "pessoal da educação" com o boleando "and" entre elas. Foram consultadas as bases de dados Scientific Electronic Library Online (SciELO), América Latina e Caribe em Ciências da Saúde Literatura (LILACS) e Banco de Dados de Enfermagem (BDENF) - por meio da Biblioteca Virtual em Saúde (BVS). A triagem e seleção dos artigos elegíveis foi realizada por dois revisores, buscando garantir rigor metodológico na seleção dos artigos nas bases dados. Foram incluídos estudos primários, em português, que apresentavam aderências ao tema proposto disponível na íntegra e publicados no período de dez anos, compreendendo 2008 a 2018. Os critérios de exclusão foram: revisão integrativa e de literatura, livros, capítulos e resenhas de livros, manuais, relatórios técnicos. Também serão excluídos artigos 
que não possuíam relação com a questão norteadora do estudo.

A triagem e seleção de artigos foram apresentadas por diagrama de fluxo de estudos e posteriormente houve extração dos conceitos abordados em cada artigo e os trabalhos de acordo com seu conteúdo. Os resultados foram apresentados qualitativamente e posteriormente discutidos com os achados da literatura. Considerando o presente estudo como secundário da literatura, não foi necessário a aprovação do Comitê de Ética em Pesquisa (CEP).

\section{RESULTADOS}

Nas buscas nas bases de dados, foram resgatados 68 artigos. Inicialmente foi realizada a triagem por título e 33 artigos foram excluídos nesta etapa. Sequencialmente a triagem seguiu pela leitura dos resumos e 6 artigos foram excluídos, por fim, 16 artigos foram incluídos para análise, conforme expressa o diagrama de fluxo de estudos selecionados (Figura 1).

Posteriormente foram extraídos os conceitos abordados em cada artigo e os trabalhos foram descritos conforme seu conteúdo, sendo a categorização temática, dividida em: Metodologias baseadas em problemas e projetos, Metodologia de Aprendizagem baseada em Projetos, Taxonomia de Bloom e Método de Delphi, Aplicativos Móveis.

\section{Metodologias baseadas em proble- mas e projetos}

Figura 1. Diagrama de fluxo dos estudos selecionados para elaboração de revisão integrativa da literatura

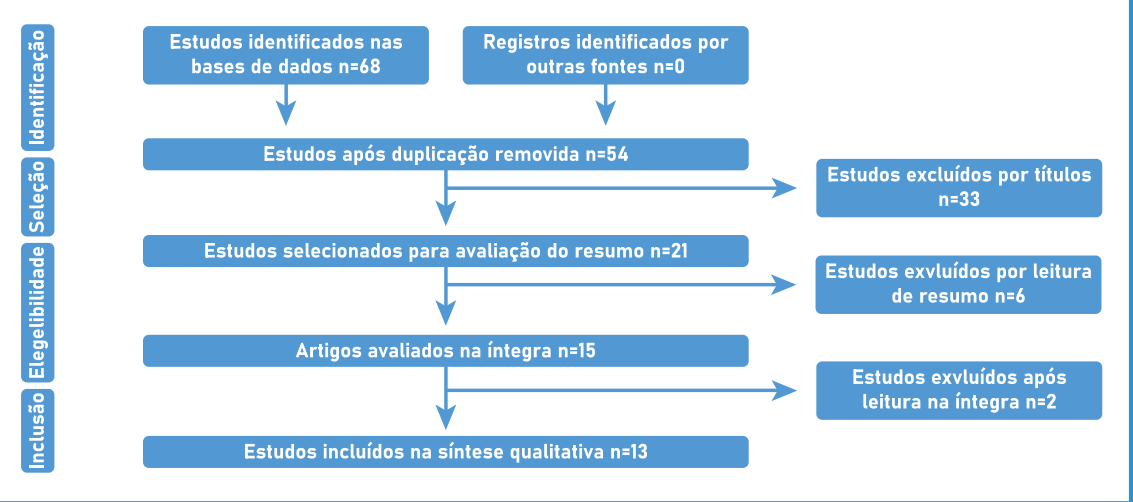

Fonte: os autores, 2020
Vivenciar as situações próximas do real pode trazer múltiplos ensinamentos. As metodologias baseadas em resolução de problemas e/ou projetos utilizam casos reais para estimular os estudantes a acionarem os conteúdos teóricos através de situações que necessitam de soluções a partir dos desafios da realidade ${ }^{(10)}$.

A Problem Basead Learning (PBL) ou Aprendizagem baseada em problemas ou projetos requer do aluno os processamentos de várias aprendizagens, como: a proatividade, trabalho em equipe, discussões e interdisciplinaridade. Ao fazer uma simulação de situações próximas do real disparam-se vários mecanismos, como raciocínio lógico, tomada de decisão, trabalho em equipe, liderança, análise do cenário, testagens e hipóteses ${ }^{(11)}$.

A PBL coloca o aluno no centro do de conhecimentos prévios, interesse e motivação para emancipar-se no caminho do conhecimento, ao mesmo tempo em que envolve o trabalho em equipe e os ciclos colaborativos, supera fronteiras inteirando-se de outros conhecimentos e envolve seus sentidos para experimentar, 'prototipar', para alcançar as soluções ${ }^{(12)}$.

A PBL não aborda só os conceitos e procedimentos que envolvem os processos cognitivos, mas também com aspectos atitudinais, ou seja, provocam respostas comportamentais nos alunos engajadas em objetivos. A PBL envolve o conceito de Pavlov sobre estímulo, resposta e reforço, processo à medida que o mesmo se utiliza

os processos da metacognição estudados pela teoria cognitiva e a reflexão sobre as próprias experiências, os quais estruturam a forma do raciocínio de tal modo que o aluno é capaz de reformular os processos mentais e obter novos insights ${ }^{(10-12)}$.

A PBL é adotada há mais de 50 anos, sobretudo nos cursos de medicina nos Estados Unidos e no Canadá, e vem adquirindo mais espaço na educação contemporânea, pois a abordagem transcende o método de memorização do conteúdo para responder às avaliações adotadas nas metodologias tradicionais, nas quais o conteúdo é rapidamente esquecido pelo educando. A PBL estimula o aprendiz a encontrar soluções e não memorizar a resposta; a utilizar os conhecimentos registrados para encontrar as "saídas", testando mental e concretamente as hipóteses, com criticidade, checando as possibilidades e, diante da testagem de forma autônoma, poder resolver as dúvidas e questionamentos ${ }^{(10)}$.

A implementação da $\mathrm{PBL}$ promove uma série de possibilidades em sala de aula, como a emancipação e o protagonismo do aluno, já que o mesmo deve ter tomada de decisão, ao mesmo tempo a multidisciplinaridade é interativa e permite a partilha de experiências e saberes, estes múltiplos processos se permeiam e enriquecem o processo ensino aprendizagem ${ }^{(10-13)}$.

O professor deve motivar os seus aprendizes para que eles se tornem ativos no processo de aprendizagem, e que busquem autonomamente enfrentar as dificuldades que se apresentam de forma compartilhada com os colegas.

\section{Metodologia de Aprendizagem ba- seada em Projetos}

A ABP pode ser utilizada como balizadoras para avaliar se as etapas que estão sendo desenvolvidas pelos alunos durante o projeto, se estão alcançando níveis de qualidade de entrega e se os níveis de domínio das competências estabelecidas nos objetivos da disciplina também estão atingindo o esperado ${ }^{(14)}$.

Para compreender a aprendizagem baseada em projeto e os significados que nela estão envolvidos, é preciso interpretar e contextua- 
lizar muitos termos utilizados nesta metodologia. O Quadro 1 apresenta concepções do docente e discentes durante uma experiência da autora na disciplina de projeto integrador em curso técnico na área da saúde.

\section{Taxonomia de Bloom e Método de Delphi}

Ao analisarmos o cenário educacional, temos professores do século XX lecionando no século XXI, existe um abismo entre os momentos, superar estas demandas compõe-se em um verdadeiro desafio aos docentes, o modelo cartesiano é desconectado do mundo atual ${ }^{(15)}$.

Uma das mais conhecidas teorias sobre reestruturação dos instrumentos pedagógicos é a Taxonomia de Bloom, a qual classifica comportamentos definidos como importantes para a aprendizagem, assim, determinando três domínios educativos: o cognitivo, o emocional e o psicomotor. A taxonomia pode auxiliar na especificação de objetivos, a fim de facilitar o planejamento de experiências de aprendizagem e o preparo de programas de avaliação ${ }^{(16)}$.

A mencionada teoria coloca de forma clara o discente como receptor, não de conhecimentos repetitivos para memorizar, mas ao ser mediado por um docente que instrui caminhos e comandos que induzem o aluno a chegar aos objetivos e diferentes níveis de aprendizagem. Por exemplo, no domínio cognitivo são utilizados os verbos: demonstrar, empregar, utilizar, resolver e traçar. Já a "compreensão" vem associada a converter, decodificar, descre- ver, distinguir e inferir. Por outro lado, quando falamos de "síntese", empregamos verbos como planejar, elaborar, coordenar, propor, desenvolver e articular. E como resultado da dinâmica, o sucesso discente na execução de determinadas ações mostra seu nível de assimilação de um conteúdo. Logo, o aluno deixa de apenar memorizar e acaba criando algo novo com o conhecimento informado e adquirido ${ }^{(17)}$.

O docente contemporâneo é convidado a cada aula a aprender com seu aprendiz e descobrir caminhos e estratégias motivadoras.

Ao longo do trajeto teórico, encontrou-se contribuições de Blomm e do Método de Delphi que, embora sejam preambulares, trazem contribuições importantes. $\mathrm{O}$ Método de Delphi é baseado no princípio de que as previsões por um grupo estruturado de especialistas são mais precisas se comparadas às provenientes de grupos não estruturados ou individuais. Cada elemento é assim isolado da influência dos restantes. Como não ocorre a presença física dos participantes numa reunião, este método pode ser usado quando os elementos do grupo se encontram distantes geograficamente ${ }^{(15)}$.

A validade de construto ou de conceito constitui a forma direta de verificar a amplitude em que a medida corresponde à construção teórica do fenômeno a ser mensurado. Embora o conceito apresentasse outros nomes, tais como, validade intrínseca, validade fatorial e até validade aparente. Estas várias terminologias demonstram a confusa noção que o construto possuía ${ }^{(16)}$.

Segundo Bloom, vários pesquisadores

\begin{tabular}{|l|l|}
\hline Quadro 1. Concepções dos discentes e docentes que se utiliza da ABP \\
\hline CERNE & \multicolumn{1}{c|}{ SIGNIFICAÇÃo } \\
\hline Concepção & O docente expõe o tema âncora, mas sem arquétipos. \\
\hline Pensamento Crítico & $\begin{array}{l}\text { Discentes refletem a partir do conhecimento empírico e } \\
\text { pregresso/tácito. }\end{array}$ \\
\hline Provocação & Problematização e contextualização. \\
\hline Ciclo Colaborativo & Docente motiva a colaboração e relacionamentos interpessoais. \\
\hline Liderança & Discentes engajados, motivados e com propósito. \\
\hline Expertise & $\begin{array}{l}\text { Docente com habilidades de multiplicar e mediar conhecimentos } \\
\text { e competências. }\end{array}$ \\
\hline Inovação & Projetos inovadores com abordagem. \\
\hline Borochovicius, Tortella; 2014 & \\
\hline
\end{tabular}

utilizaram-se dessa terminologia conceitual baseada em classificações estruturadas e orientadas para definir algumas teorias instrucionais ${ }^{(18)}$.

Duas das inúmeras vantagens de se utilizar a taxonomia no contexto educacional são:

- Oferecer a base para o desenvolvimento de instrumentos de avaliação e utilização de estratégias diferenciadas para facilitar, avaliar e estimular o desempenho dos alunos em diferentes níveis de aquisição de conhecimento;

- Estimular os educadores a auxiliarem seus discentes, de forma estruturada e consciente, a adquirirem competências específicas a partir da percepção da necessidade de dominar habilidades mais simples (fatos) para, posteriormente, dominar as mais complexas - conceitos $^{(9)}$.

\section{Aplicativos Móveis}

Pensando em um cenário prospectivo e diante da importância da temática e rápida evolução no desenvolvimento tecnológico dos dispositivos móveis, acredita-se que novas estratégias e metodologias educacionais serão desenvolvidas, aprimoradas e colocadas em uso, demandando cada vez mais estudos e pesquisas avaliativas que produzam evidências sobre a sua efetividade ${ }^{(19)}$.

O uso de aplicativos móveis na educação, gestão de cuidados, ferramentas de diagnóstico é inovador, reforçando e motivando o interesse em aprender. Os dispositivos móveis que hospedam esses aplicativos são utilizados por $45 \%$ a $85 \%$ dos profissionais de saúde em todo o mundo e são agora mais comumente empregados do que livros e revistas ${ }^{(19,20)}$.

No contexto atual, as Tecnologias da Informação e Comunicação (TICs) voltadas para a área da saúde possuem diversas ferramentas que apoiam a estruturação e a organização dos dados e informações, possibilitando o armazenamento, processamento, acesso em tempo real e/ou remoto e compartilhamento dos mesmos, seja pelos diversos profissionais envolvidos na assistência, bem como, pelo próprio paciente/usuário ${ }^{(21)}$. 
Neste cenário, destacam-se o fenômeno das tecnologias móveis (tablets, smartphones etc.), especialmente da utilização de aplicativos móveis (também conhecidos como Apps - do inglês Application) entre a população mundial. Os Apps são conceituados como um conjunto de ferramentas desenhado para realizar tarefas e trabalhos específicos. Tais características agregam valor estratégico para a nova sociedade da Era da Informação ${ }^{(22,23)}$.

O aprendizado mediado por tecnologias para profissionais de saúde tem sido extremamente explorado em alguns países ocidentais que as consideram ferramentas eficazes e úteis se comparadas aos métodos tradicionais.

Ressalta-se a importância de reconhecer novos formatos e pensar em projetos que não apenas sejam para consumir informação em deslocamento, mas também de produzir e distribuir a informação. Os dispositivos móveis ampliam essa possibilidade e torna imprescindível para inclusão social na sociedade da informação ${ }^{(24)}$.

\section{DISCUSSÃO}

As metodologias ativas de ensino e aprendizagem estão fundamentadas na ideia do estudante como responsável pela própria busca do conhecimento, cabendo ao professor o papel de facilitador e estimulador desta busca ${ }^{(8)}$.

De forma resumida, pode-se afirmar que no ambiente de aprendizagem da $\mathrm{PBL}$, o docente tem um papel para além da transmissão de conhecimento técnico, mas, sobretudo o papel de facilitador comportamental focado em resultados estimulando os alunos a tentarem superar seus limites e transporem barreiras psicológicas que possam impedi-los de alcançar os objetivos desejados ${ }^{(25)}$.

A metacognição envolve o conhecimento cognitivo real, assim como a consciência da aprendizagem individual. Essa subcategoria tem se tornado cada vez mais importante na área educacional uma vez que a possibilidade de autoaprendizagem e o controle do aprendizado relacionado à autonomia de aprender devem ser um processo cada vez mais consciente e passível de medição. Isso é possibilitado pela utilização da tecnologia da comunicação na educação, a criação de novas oportunidades educacionais e a popularização da modalidade à distância ${ }^{(26)}$.

\section{$\mathrm{O}$ aprendizado}

mediado por

tecnologias para

profissionais de

saúde tem sido

extremamente

explorado em alguns

países ocidentais

que as consideram

ferramentas eficazes

e úteis se comparadas

aos métodos

tradicionais.

No âmbito das tecnologias, o desenvolvimento científico e tecnológico acelerado no setor da saúde tem criado formas de construir conhecimento sobre as atividades diárias dos serviços de enfermagem. Os avanços na tecnologia computacional são esperados para melhorar os processos organizacionais em todos os níveis, nos próximos anos, proporcionando benefícios operacionais e estratégicos às instituições e à prática de enfermagem ${ }^{(27)}$.
Dessa forma, trabalhar com o uso dos dispositivos não se torna apenas uma necessidade, mas também um cenário positivo de inserção no cotidiano desses profissionais. A escolha da tecnologia móvel para aplicativo se dá pela praticidade, inovação tecnológica e por ser este um instrumento presente no cotidiano das pessoas. Estes fatos conferem à ferramenta um grande potencial para a utilização como apoio ao processo de ensino e aprendizagem ${ }^{(27,28)}$.

\section{CONCLUSÕES}

O homem é um ser que se relaciona com o mundo de modo consciente, intencional, reflexivo e potencialmente responsável. É capaz de fazer juízos de valor sobre sua própria forma de ser e agir e a dos demais seres humanos. Pelo pensamento, pela linguagem e pelo trabalho, o homem dá sentido, conhece e modifica o mundo, entendido como o ambiente ou circunstância no qual o homem vive, convive e transforma pela sua ação.

É necessário que se busque um ensino inovador que ofereça a experiência mais próxima possível da situação real e a visualização do manuseio prático, o que pode ser obtido por meio de tecnologias digitais. Dentre essas tecnologias, destacam-se os ambientes multimídia, que permitem a comunicação entre o indivíduo e o computador, pelo uso de múltiplos meios de representação da informação, como textos, imagens, sons, animações e vídeos.

O professor tradicional cartesiano torna-se ultrapassado, ele tolhe o aluno em suas perspectivas de criação e reflexão. É possível detectar a falta de conhecimento e recursos de muitos docentes para a utilização das MAEAs, o que o deixa a margem de infinitas possibilidades. Tomarmos posse das metodologias atuais, inovação tecnológica a favor da educação nos parece o caminho a ser seguido. As metodologias ativas retomam o âmago da formação educativa humana que prepara o homem para mundo, para sociedade. Não se trata de deixar boas práticas antigas, mas adaptar-se ao novo movimento que nos toma.

O papel do professor, enquanto facilita- 
dor no processo de ensino-aprendizagem, é fundamental no sentido de adequar-se às novas demandas, abrir-se para as novas práticas pedagógicas, aceitar os desafios que a educação de hoje e do futuro imprimem, ensinar a aprender e aprender para ensinar. e juntos, docente e discente, construir o processo ensino aprendizagem trata-se de uma responsabilidade mútua.

\section{REFERÊNCIAS}

1. Jaeger W. Paidéia. A formação do homem grego. Tradução Artur M. Parreira. São Paulo: Martins Fontes; 1995.

2. Repetto MA, Souza MF. Avaliação da realização e do registro da Sistematização da Assistência de enfermagem (SAE) em um hospital universitário. Rev Bras Enferm. 2005; 58(3): 325-9. https://doi. org/10.1590/S0034-71672005000300014

3. Gemignani EYMY. Formação de Professores e Metodologias Ativas de Ensino aprendizagem: Ensinar Para a Compreensão. Revista Fronteira da Educação [Internet]. 2012 [acesso em 05 nov 2020];1(2). Disponivel em: https://www.uniavan.edu.br/uploads/ arquivo/K2t3kZ.pdf

4. Araújo UF, Sastre G (Org.). Aprendizagem Baseada em Problemas no ensino superior. SP: Summus; 2009.

5. Decker I, Bouhuijs P. Aprendizagem baseada em problemas e metodologia de problematização: Identificando e analisando continuidades e descontinuidades no processo de ensino aprendizagem. In U. Araújo, \& G. Sastre, Aprendizagem Baseada em Probelmas no ensino superior ( $2^{\mathrm{a}}$ ed., pp. 177-204). São Paulo (Brasil): Summus Editorial; 2009.

6. Marin MJS, et al. Aspectos das fortalezas e fragilidades no uso das metodologias ativas de aprendizagem. Rev. bras. educ. med. 2010; 34(1):13-20.

7. Freire P. Pedagogia da autonomia: saberes necessários à prática educativa. 33 ed. São Paulo: Paz e Terra; 2006.

8. Rocha HM, Lemos WM. Metodologias ativas: do que estamos falando? Base conceitual e relato de pesquisa em andamento. Simped: IX Simpósio Pedagógico em comunicação, 2014.

9. Mendes KDS, Silveira RCCP, Galvão CM. Revisão integrativa: método de pesquisa para a incorporação de evidências na saúde e na enfermagem. Texto Cont Enferm. 2008; 17(4):758-64.

10. Salinitri FD, et al. Facilitando Facilitadores: Melhorando o PBL através de um Programa de Desenvolvimento de Facilitador Estruturado. Jornal Interdisciplinar de Aprendizagem Baseada em Problemas. 2015; 9(1)

11. Wood EJ. Problem-Based Learning: Exploiting Knowledge of how People Learn to Promote Effective Learning. Bioscience Education. 2004; 3(1):1-12. https://doi.org/10.3108/beej.2004.03000006

12. Bender W N. Aprendizagem baseada em projetos: educação diferenciada para o século XXI. Tradução Fernando de Siqueira Rodrigues. Porto Alegre: Penso; 2014.

13. Angelo MF, Loula AC, Bertoni FC, Santos JAM. Aplicação e avaliação do método $\mathrm{PBL}$ em um componente curricular integrado de programação de computadores. Revista de Ensino de Engenharia.2014; 33(2).

14. Lianda RL, Pelachim JB. Aplicação da metodologia aprendizagem baseada em projetos (ABP) na disciplina química orgânica por meio do estudo de méis. Revista Ibero-Americana de Estudos em
Educação.2018; 407-420.

15. de Campos LC.Análise das Abordagens PBL e PLE na Educação em Engenharia com Base na Taxonomia de Bloom e no Ciclo de Aprendizagem de Kolb. International Journal on Alive Engineering Education.2014; 1(1), 37-46.

16. Anderson LW, et. al. A taxonomy for learning, teaching, and assessing: a revison of Bloom's Taxonomy of Educational Objectives. Nova York: Addison Wesley Longman; 2001. 336 p.

17. Pinto R A. Métodos de Ensino e Aprendizagem sob a Perspectiva da Taxonomia de Bloom. Revista Contexto \& Educação.2015; 30(96), 126-155.

18. Ferraz APDC, Belhot RV. Taxonomia de Bloom: revisão teórica e apresentação das adequações do instrumento para definição de objetivos instrucionais. Gestão \& Produção.2010; 17(2), 421-431.

19. Galvão ECF, Puschel VAA. Aplicativo multimídia em plataforma móvel para o ensino da mensuração da pressão venosa central. Rev Esc Enferm USP. 2012; 46(Spe.)107-115. https://doi.org/10.1590/ S0080-62342012000700016

20. Guimarães EMP, Godoy SCB. Telenfermagem - Recurso para assistência e educação em enfermagem. Rev Min Enferm [Internet]. 2012 [05 nov 2020]; 16(2):157-8. Disponivel em: http://www.reme. org.br/artigo/detalhes/513

21. Banos O, Villalonga C, et al. Design, implementation and validation of a novel open framework for agile development of mobile health applications. Biomed Eng Online [Internet]. 2015 [acesso em 05 nov 2020]; 8:10-24. Disponivel em: https://www.ncbi.nlm.nih. gov/pmc/articles/PMC4547155/

22. Saccol A, Schlemmer E, Barbosa J. M-learning e U-learning Novas perspectivas da aprendizagem móvel e ubíqua. São Paulo: Pearson Prentice Hall; 2011.

23. Princewater HC. Touching Lives through Mobile Health: Assessment of the Global Market Opportunity. PwC, 2012.

24. Cruz NS, et al. Enfermagem, competência técnica de universitários em informática. Rev Esc Enferm USP. 2011; 45(Spe):15951599. https://doi.org/10.1590/S0080-62342011000700009

25. Escrivão FE, Ribeiro LRDC. Inovando no ensino de administração: uma experiência com a Aprendizagem Baseada em Problemas (PBL). Cadernos EBAPE. 2008; BR, 6(SPE), 01-09.

26. Davis C, Nunes M M, Nunes CA. Metacognição e sucesso escolar: articulando teoria e prática. Cadernos de pesquisa.2005; 35(125), 205-230.

27. Kenski VM. Aprendizagem mediada pela tecnologia. Revista diálogo educacional.2003; 4(10), 1-10.

28. Marçal E, Andrade R, Rios R.Aprendizagem utilizando dispositivos móveis com sistemas de realidade virtual. RENOTE-Revista Novas Tecnologias na Educação.2005; 3(1). 